\title{
FRAÇÃo DE ÁGUA TRANSPIRÁVEL DO SOLO E SUA INFLUÊNCIA NO DESENVOLVIMENTO DO NÚMERO DE FOLHAS DO CAFEEIRO JEQUITIBÁ
}

\author{
Wilian Rodrigues Ribeiro ${ }^{1}$ \\ Vinicius Agnolette Capelini² \\ Daniel Soares Ferreira ${ }^{3}$ \\ André Alves Pinheiro ${ }^{4}$ \\ Rogério Rangel Rodrigues ${ }^{5}$ \\ Edvaldo Fialho dos Reis ${ }^{6}$
}

Resumo: O déficit hídrico é o fator abiótico que mais limita a produtividade agrícola no mundo. Sabendose disto, objetivou-se neste experimento avaliar a influência do déficit hídrico pela metodologia da fração de água transpirável do solo (FATS), sob a variável de desenvolvimento número de folhas (NF) do cafeeiro conilon clonal. Foi instalado um experimento com a cultura do cafeeiro conilon (Coffea canephora) utilizando 3 clones da variedade Jequitibá Incaper ES 8122. Procedeu-se a condução do experimento em um esquema fatorial $3 \times 2$, sendo clones em 3 níveis e déficit hídrico em 2 níveis, em um delineamento inteiramente casualizado com 4 repetições. Os 2 níveis de déficit hídrico foram (TO - irrigado durante todo o experimento, não sofrerá déficit hídrico; T1 - déficit hídrico induzido até as plantas atingirem 10\% da transpiração relativa do tratamento TO). Verificou-se que os clones possuem necessidades hídricas diferentes e cada um respondeu de forma especifica de acordo com o decréscimo da FATS, resposta obtida através do comportamento da variável em estudo.

Palavras-chave: Manejo da Irrigação; Conilon Jequitibá; FATS; Irrigação.

\footnotetext{
${ }^{1}$ Agronomia/Universidade Federal do Espírito Santo, Brasil. E-mail: wilianrodrigues@msn.com.

2 Agronomia/Universidade Federal do Espírito Santo, Brasil. E-mail: vinicius91ac@hotmail.com.

3 Agronomia/Universidade Federal do Espírito Santo, Brasil. E-mail: danielufes@live.com.

${ }^{4}$ Agronomia/Universidade Federal do Espírito Santo, Brasil. E-mail: aalvespinheiro7@gmail.com.

${ }^{5}$ Agronomia/Universidade Federal de Lavras, Brasil. E-mail: rogeriorr7@hotmail.com.

${ }^{6}$ Agronomia/Universidade Federal do Espírito Santo, Brasil. E-mail: edreis@cca.ufes.br.
} 